\title{
Visitantes florais de Lagerstroemia speciosa Pers. (Lythraceae)
}

\author{
Maria de Jesus Vitali-Veiga ${ }^{1}$ \\ João Cloves Stanzani Dutra ${ }^{1}$ \\ Vera Lígia Letizio Machado ${ }^{1,2}$
}

\begin{abstract}
Floral visitors in Lagerstroemia speciosa Pers. (Lythraceae). Studies were carried out with Lagerstroemia speciosa Pers. on floral reproductive systems, diversity and constancy of visiting insects at different hours of day, the behaviour of these insects at the flowers and the influence of these environmental factors in relation to their visits. The fenology, anthesis and others particularity of this vegetal species was studied. A great diversity of insects was verified visiting the flowers with the predominance of bees. The most frequent and constant species encountered were: Nannotrigona testaceicornis (Lepeletier, 1836) (40,2\%), Tetragonisca angustula (Latreille, 1811) (16,9\%), Apis mellifera Linnaeus, 1758 (11,8\%), Plebeia droryana (Friese, 1900) (9,1\%)e Exomalopsis fulvofasciata (Smith, 1879) (8,5\%). The blossoms possessis features of melittophily syndrome and diurnal anthesis. The environmental factors influence the insects foraging activity, mainly temperature, light, time of day, humidity and wind speed. The effective pollinators were the large insects like Bombus morio (Swederus, 1787), Bombus atratus (Franklin, 1913), Centris tarsata (Smith, 1874), Centris flavifrons Fabricius, 1775, Xylocopa suspecta Camargo \& Moure, 1988, Xylocopa frontalis (Olivier, 1789) and Eulaema nigrita Lepeletier, 1841.

KEY WORDS. Bee, flower visitors, phenology, pollination, Lagerstroentia speciosa
\end{abstract}

Durante o processo de urbanização, geralmente se verifica a ocupação crescente das áreas de vegetação natural com a destruição dos muitos locais de nidificação das abelhas e das fontes de alimento, resultando na diminuição de suas populações.

Um dos aspectos importantes que atrai a atenção para o estudo da comunidade de abelhas em ecossistemas alterados relaciona-se a possibilidade destes locais estarem se tornando "refúgios" para algumas espécies que não dispõem mais de seus ambientes naturais.

As abelhas são visitantes florais por excelência, pois a sua alimentação, da fase larval à adulta, depende basicamente das flores. Esta visita floral é motivada pela oferta de alimento, na forma de néctar e/ou pólen, por diversas espécies vegetais, em troca do benefício da polinização.

O presente estudo objetiva fornecer informações a respeito do comportamento da entomofauna visitante em relação a Lagerstroemia speciosa Pers.; identifica-

1) Centro de Estudos de Insetos Sociais, Instituto de Biociências, Universidade Estadual Paulista. Avenida 24-A 1515, Caixa Postal 199, 13506-900 Rio Claro, São Paulo, Brasil.

2) Pesquisadora do CNPq. 
ção dos polinizadores e dos visitantes florais mais freqüentes correlacionando-os com os horários do dia e fatores ambientais; biologia floral e reprodução desta espécie, considerando a escassez de conhecimentos desta natureza. Trata-se de uma árvore originária da Índia e aclimatada no Brasil, muito utilizada na arborização de ruas em virtude de seu pequeno porte e flores rosadas delicadas, que atraem muitos visitantes.

\section{MATERIAL E MÉTODOS}

As coletas foram realizadas em cinco plantas de Lagerstroemia speciosa (L1, L2, L3, L4 e L5) localizadas no jardim da Universidade Estadual Paulista, Rio Claro, São Paulo. Lagerstroemia speciosa é comumente utilizada na arborização de parques, ruas e jardins, mas pouco se conhece de sua ecologia da polinização.

As coletas dos insetos visitantes foram feitas durante a floração do ano de 1990, durante o período forrageador, ou seja, das 8:00 às 18:00 horas, anotando-se para cada horário os seguintes fatores ambientais: luminosidade, temperatura, velocidade do vento, pressão barométrica e umidade relativa do ar.

A fenologia da planta foi determinada através das seguintes fenofases: queda foliar, brotação, floração e frutificação. Os resultados obtidos foram lançados por mês de observação e com esses dados construiu-se um calendário fenológico para a espécie.

As estruturas florais foram identificadas, descritas e desenhadas no laboratório, com auxílio de um estereomicroscópio. O acompanhamento das modificações florais foi realizado marcando com fita crepe diversas flores prestes a se abrirem e anotou-se o período de duração das mesmas e o horário da antese (abertura da flor) até a senescência (queda das pétalas). Realizou-se a contagem das flores e dos frutos produzidos por inflorescência $(\mathrm{n}=10)$. A receptividade do estigma foi avaliada pelo despreendimento de bolhas de ar ao colocar-se algumas gotas de água oxigenada (20 vol.) sobre a superfície estigmática, ou pelo aspecto umectante do mesmo. A viabilidade dos grãos de pólen foi verificada utilizando-se o método de RADFORD et al. (1974), onde o conteúdo da antera (recém-deiscente) foi removido para uma lâmina de microscopia contendo uma gota de carmim acético. Posteriormente, observou-se ao microscópio os grãos de pólen viáveis (corados de vermelho), calculando-se o percentual através de amostragem de dez campos. Detectou-se a presença de células produtoras de odor (osmóforos) utilizando-se o método de Vogel (1962 apud Oliveira-FilHo \& Oliveira 1988) que cora as flores com vermelho neutro. $\mathrm{O}$ tipo de odor foi verificado mantendo algumas flores em sacos plásticos fechados durante uma hora para concentrar a substância odorífera. Com auxílio de um refratômetro, mensurou-se a concentração de açúcares contidos no néctar. Os locais da flor que absorvem e refletem os raios ultravioleta foram detectados utilizando uma solução de éter sulfúrico a 1\% (VOGEL 1983) que impregna de preto estas regiões florais.

Para testar o efeito dos polinizadores, 125 flores ainda em botão foram envolvidas isoladamente em sacos de papel impermeável. Durante a pré-antese, parte dessas flores foi emasculada $(n=25)$ para se testar a apomixia. Outra parte das 
flores $(\mathrm{n}=25)$ foi polinizada manualmente com pólen da mesma flor e também com pólen proveniente de flores diferentes $(n=25)$ da mesma planta, para se testar a autopolinização e geitonogamia, respectivamente. Através da transferência de pólen de flores de plantas diferentes testou-se a polinização cruzada $(n=25)$. Para a verificação da existência ou não de autopolinização espontânea, outras flores ensacadas $(n=25)$ permaneceram intactas.

Todas estas flores com seus respectivos tratamentos tiveram seu desenvolvimento acompanhado até a formação de frutos. Posteriormente, o número de frutos e sementes produzidos foram contados.

O comportamento dos visitantes mais freqüentes (acima de 5\% do total) foi observado e classificado segundo a terminologia de INOUYE (1980). As espécies visitantes mais freqüentes foram correlacionadas com os parâmetros ambientais aplicando-se o teste de correlação de Spearman.

\section{RESULTADOS E DISCUSSÃO}

Durante o mês de agosto, a maioria das plantas de Lagerstroemia speciosa encontra-se quase sem folha alguma. O desenvolvimento das gemas florais que originam as inflorescências ocorre nos meses de setembro/outubro. Sua floração é maciça (após o aparecimento das primeiras flores abertas, todas as plantas da espécie tornam-se floridas) e tem início em outubro, atingindo intensidade máxima em novembro, com término em dezembro (Tab. I) As flores são hermafroditas, de tamanho médio. A corola é aberta e rasa, composta por pétalas radiais crespas de coloração rósea, com androceu formado por muitos estames livres, gineceu com ovário súpero e numerosos óvulos. Dessa forma, podem ser visitadas por diferentes grupos de animais com diversos níveis de adaptação quanto a sua morfologia.

Tabela I. Fenologia de Lagerstroemia speciosa Pers. (Lythraceae) durante os meses do ano de 1990.

\begin{tabular}{|c|c|c|c|c|c|c|c|c|c|c|c|c|}
\hline \multirow{2}{*}{ Fenofases } & \multicolumn{12}{|c|}{ Mese do ano } \\
\hline & Jan & Fev & Mar & $\mathrm{Abr}$ & Mai & Jun & Jul & Ago & Set & Out & Nov & Dez \\
\hline Desenvolvimento das gemas florais & & & & & & & & & *** & * & & \\
\hline Floraçăo & & & & & & & & & & $* *$ & $* * *$ & $* \star \star$ \\
\hline Frutos pequenos e verdes & $* * *$ & $* * *$ & *** & & & & & & & & & $*$ \\
\hline Frutos desenvolvidos & & & & ** & $* * *$ & & & & & & & \\
\hline Frutos totalmente abertos & & & & & ** & $\star \star \star *$ & $* * *$ & & & & & \\
\hline Queda das sementes & & & & & ** & $* \star *$ & $* * *$ & $* \star *$ & $\star \star * *$ & $* * *$ & & \\
\hline Surgimento das primeiras folhas & & & & & & & & & ** & $* * *$ & ** & \\
\hline Desenvolvimento e crescimento da planta & & & & & & & & & * & $* *$ & $* * *$ & \\
\hline Queda das folhas & & & & & & $\star *$ & $* * *$ & $\star \star * *$ & & & & \\
\hline
\end{tabular}

*) Registro a cada 10 dias do mês.

A antese das flores é diurna, geralmente ocorre entre 8:30 a 10:30 horas e permanece aberta por dois a três dias. No início da antese (Fig. 1A) as anteras apresentam-se com $98 \%$ de viabilidade dos grãos de pólen. Após duas a três horas, ocorre a receptividade do estigma. Glândulas de odor, foram observadas espalhadas por toda corola, o que lhe confere aroma suavemente adocicado. A concentração de 
açúcar presente no néctar é de $2 \%$ a $26^{\circ} \mathrm{C}(\mathrm{n}=10)$. Na pós-antese, os estames esgotados de pólen enovelam-se ao redor do estilete (Fig. 1B) que se apresenta, nesta etapa, pouco úmido e sem brilho. As flores tornam-se desbotadas (esbranquiçadas), flácidas, enrugadas e caem. O filete e estiletes tornam-se escurecidos e, juntamente com o cálice, permanecem na inflorescência. Em média, são produzidas 16,06 flores e 9,8 frutos por inflorescência. Verifica-se a formação de frutos na porção inferior da inflorescência (Fig. 1C).
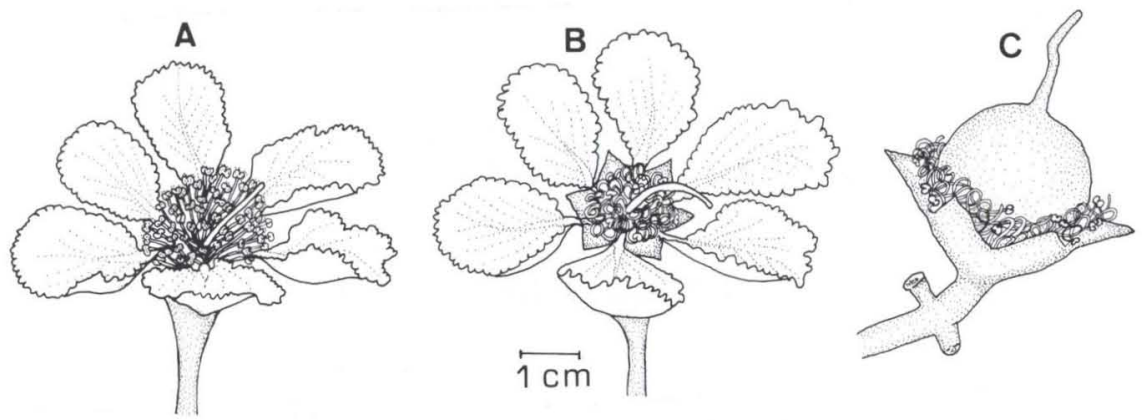

Fig. 1. Aspecto geral da flor de Lagerstroemia speciosa Pers. (Lythraceae). (A) Antese, (B) pós-antese, (C) fruto.

A tabela II apresenta o total de insetos coletados: 97,5\% Hymenoptera, 1,4\% Coleoptera e 1,1\% representam a soma de Lepidoptera, Diptera, Hemiptera e Homoptera.

Tabela II. Visitantes florais de Lagerstroemia speciosa Pers. (Lythraceae).

\begin{tabular}{|c|c|c|c|c|c|c|}
\hline \multirow{2}{*}{ Insetos } & \multicolumn{6}{|c|}{ Plantas } \\
\hline & L1 & L2 & L3 & L4 & L5 & Total \\
\hline \multicolumn{7}{|l|}{ Hymenoptera } \\
\hline \multicolumn{7}{|l|}{ Apidae } \\
\hline Apis mellifera Linnaeus, 1758 & 56 & 67 & 76 & 65 & 25 & 289 \\
\hline Trigona spinipes (Fabricius, 1793) & 1 & - & - & - & - & 1 \\
\hline Melipona quadrifasciata Lepeletier, 1836 & - & - & 1 & - & - & 1 \\
\hline Nannotrigona testaceicornis (Lepeletier, 1836) & 73 & 52 & 509 & 255 & 95 & 984 \\
\hline Tetragonisca angustula (Latreille, 1811) & 17 & 50 & 172 & 140 & 35 & 414 \\
\hline Plebeia droryana (Friese, 1900) & 5 & 12 & 108 & 69 & 29 & 223 \\
\hline Plebeia schrottkyi (Friese, 1900) & - & 1 & 2 & 2 & - & 5 \\
\hline Frieseomellita sp. & - & - & - & 1 & - & 1 \\
\hline Bombus morio (Swederus, 1787) & 1 & 2 & 3 & - & - & 6 \\
\hline Bombus atratus Franklin, 1913 & - & - & - & - & 1 & 1 \\
\hline Eulaema nigrita Lepeletier, 1841 & - & - & 1 & - & - & 1 \\
\hline Megachilidae & - & - & - & 2 & - & 2 \\
\hline Anthophoridae & - & 1 & 5 & - & - & 6 \\
\hline Exomalopsis fulvofasciata (Smith, 1879) & 24 & 8 & 70 & 82 & 24 & 208 \\
\hline Centris analis (Fabricius, 1804) & - & - & 1 & - & - & 1 \\
\hline Centris flavifrons Fabricius, 1775 & - & - & 5 & 2 & - & 7 \\
\hline Centris tarsata Smith, 1874 & 1 & - & - & - & - & 1 \\
\hline Xylocopa suspecta Camargo \& Moure, 1988 & 1 & 3 & 16 & 2 & 1 & 23 \\
\hline Xylocopa frontalis (Olivier, 1789) & - & 1 & - & - & - & 1 \\
\hline Thygater analis (Lepeletier, 1841) & - & - & 1 & - & - & $\begin{array}{r}1 \\
\text { (Con }\end{array}$ \\
\hline
\end{tabular}


Tabela II. Continuação

\begin{tabular}{|c|c|c|c|c|c|c|}
\hline \multirow{2}{*}{ Insetos } & \multicolumn{6}{|c|}{ Plantas } \\
\hline & L1 & L2 & L3 & L4 & L5 & Total \\
\hline Halictidae & 1 & - & 9 & 21 & - & 31 \\
\hline Augochlora esox (Vachal, 1911) & - & 3 & 2 & 1 & - & 6 \\
\hline Pseudaugochloropsis sp. & 2 & - & 1 & - & 1 & 4 \\
\hline Pseudaugochloropsis graminea (Fabricius, 1804) & - & - & 1 & - & - & 1 \\
\hline Augochloropsis sp. & - & 5 & 22 & 1 & 2 & 30 \\
\hline \multicolumn{7}{|l|}{ Andrenidae } \\
\hline Oxaea flavescens Klug, 1807 & 1 & - & 1 & 2 & - & 4 \\
\hline \multicolumn{7}{|l|}{ Formicidae } \\
\hline Camponotus sp. & 8 & 3 & - & 2 & 1 & 14 \\
\hline Pseudomyrmex sp. & 3 & 1 & - & - & 1 & 5 \\
\hline Solenopsis sp. & 1 & - & - & - & - & 1 \\
\hline Myrmicinae & - & - & - & 5 & - & 5 \\
\hline Megachilidae & - & - & - & 2 & - & 2 \\
\hline Ichneumonidae & - & 1 & - & - & - & 1 \\
\hline Sphecidae & - & - & - & 1 & - & 1 \\
\hline \multicolumn{7}{|l|}{ Vespidae } \\
\hline Protonectarina sylveirae (de Saussure, 1854) & 4 & 11 & 6 & 8 & 5 & 34 \\
\hline Polybia paulista H. von Ihering, 1896 & 5 & 5 & 2 & 6 & 8 & 26 \\
\hline Mischocyttarus cerberus styx Richards, 1940 & 1 & - & - & - & - & 1 \\
\hline Protopolybia exigua (de Saussure, 1854) & 3 & 7 & 6 & 3 & 3 & 22 \\
\hline Polybia ignobilis (Haliday, 1836) & - & 2 & 1 & 1 & - & 4 \\
\hline Polistes lanio (Fabricius, 1775) & - & - & 2 & 2 & 2 & 6 \\
\hline Polistes versicolor (Olivier, 1791) & - & - & 1 & - & 1 & 2 \\
\hline Protopolybia sedula (de Saussure, 1854) & - & - & - & 3 & - & 3 \\
\hline Brachygastra lecheguana (Latreille, 1824) & - & - & - & 2 & - & 2 \\
\hline Pachodynerus sp. & - & 2 & - & 2 & 3 & 7 \\
\hline \multicolumn{7}{|l|}{ Lepidoptera } \\
\hline Hesperiidae & - & - & - & 1 & - & 1 \\
\hline \multicolumn{7}{|l|}{ Danaidae } \\
\hline Methona themisto $(\mathrm{Hbn} ., 1818)$ & 1 & - & - & - & - & 1 \\
\hline \multicolumn{7}{|l|}{ Diptera } \\
\hline Syrphidae & - & - & 1 & - & - & 1 \\
\hline Muscidae & 3 & 1 & - & 2 & - & 6 \\
\hline Tephritidae & 4 & 1 & 2 & - & - & 7 \\
\hline Calliphoridae & 1 & 1 & - & - & - & 2 \\
\hline Sarcophagidae & - & - & 3 & - & - & 3 \\
\hline Stratiomyidae & - & - & 1 & - & - & 1 \\
\hline \multicolumn{7}{|l|}{ Coleoptera } \\
\hline Carabidae & 1 & - & - & - & - & 1 \\
\hline Curculionidae & 1 & - & - & 1 & 1 & 3 \\
\hline Coccinelidae & - & 1 & 3 & - & - & 4 \\
\hline Nitidulidae & 1 & 1 & - & 2 & 2 & 6 \\
\hline Chrysomelidae & - & - & 8 & - & - & 8 \\
\hline Diabrotica speciosa (Germar, 1824) & - & - & 2 & - & - & 2 \\
\hline Tenebrionidae & - & - & - & 1 & - & 1 \\
\hline Cerambycidae & - & - & - & 1 & - & 1 \\
\hline Scolytidae & - & - & - & 6 & 1 & 7 \\
\hline \multicolumn{7}{|l|}{ Hemiptera } \\
\hline Coreidae & - & 1 & - & - & - & 1 \\
\hline Phthia sp. & - & - & - & - & 2 & 2 \\
\hline Reduvidae & - & - & - & 1 & - & 1 \\
\hline \multicolumn{7}{|l|}{ Homoptera } \\
\hline Cicadellidae & - & - & - & 1 & - & 1 \\
\hline Total & 220 & 243 & 1044 & 696 & 243 & 2446 \\
\hline
\end{tabular}




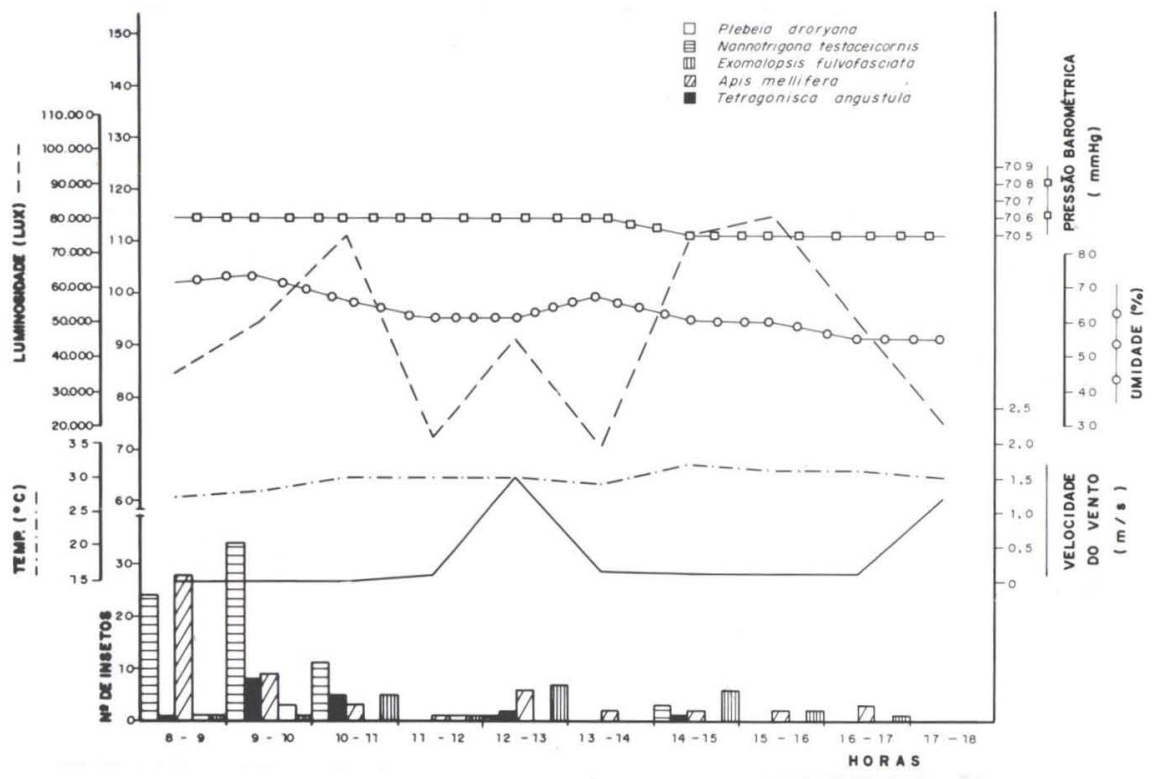

Fig. 2. Distribuição das cinco espécies de abelhas mais freqüentes em diferentes horários, correlacionando com a luminosidade, temperatura, velocidade do vento, umidade e pressão barométrica da coleta 1 realizada na planta L1 durante o período de floração de Lagerstroemia speciosa Pers. (Lythraceae) no ano de 1990.

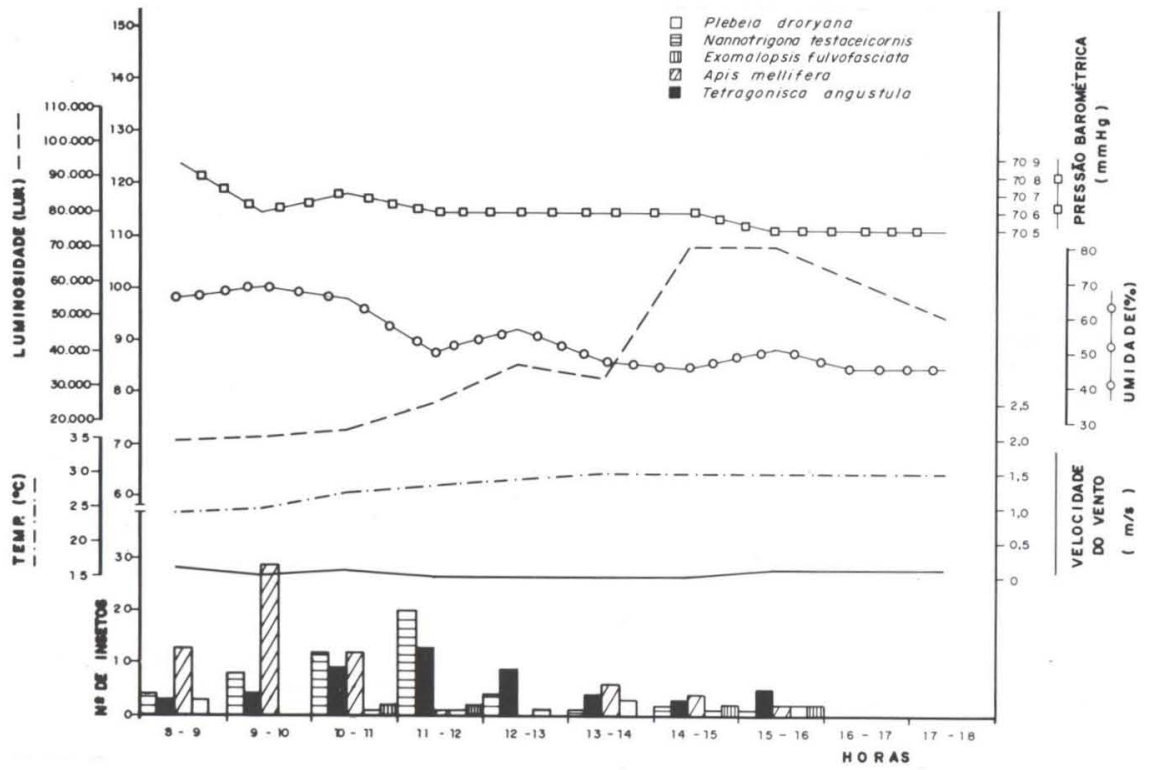

Fig. 3. Distribuição das cinco espécies de abelhas mais freqüentes em diferentes horários, correlacionando com a luminosidade, temperatura, velocidade do vento, umidade e pressão barométrica da coleta 2 realizada na planta L2 durante o período de floração de Lagerstroemia speciosa Pers. (Lythraceae) no ano de 1990. 
Foram dominantes, em número de indivíduos, cinco espécies de abelhas: Nannotrigona testaceicornis (Lepeletier, 1836) (40,2\%), Tetragonisca angustula (Latreille, 1811) (16,9\%), Apis mellifera Linnaeus, 1758 (11,8\%), Plebeia droryana (Friese, 1900) (9,1\%) e Exomalopsis fulvofasciata (Smith, 1879) (8,5\%). Estas espécies foram as mais abundantes e ocorrem em todas as coletas. Apesar do pequeno tamanho corpóreo em relação ao tamanho da flor, exploraram de forma intensa grande quantidade de flores. Não foi observada competição entre essas abelhas e, muitas vezes, A. mellifera, $T$. angustula e $P$. droryana foram vistas forrageando a mesma flor. Também, entre as grandes abelhas observou-se Bombus aguardando para pousar em uma flor que estava sendo visitada por Centris. Isto porque, a maior recompensa que essa planta oferece é o pólen e todas as abelhas saem das flores com o corpo e pernas carregadas deste material. Segundo FrEE (1980) a atratividade de uma florada depende de muitos fatores e dentre eles estão a qualidade e a quantidade de pólen produzido por flor, a concentração e quantidade de néctar, a concentração e abundância das flores, o número de insetos competidores, a atratividade de floradas competidoras, a distância da florada à colônia, as necessidades da colônia e a preferência floral inata da colônia. Portanto, todos esses fatores estão sujeitos a variações, de modo que a atratividade de uma florada pode diferir em circunstâncias diversas.

As figuras 2 a 6 mostram o interrelacionamento das variáveis ambientais com cada um dos exemplares de L. speciosa estudados, além das cinco espécies de abelhas mais abundantes. Através do teste de correlação de Spearman, $N$. testaceicornis apresentou correlações significativas positivas com a umidade ( $\mathrm{rs}=0,559), T$. angustula $(\mathrm{rs}=0,726), P$. droryana $(\mathrm{rs}=0,711)$, E. fulvofasciata $(\mathrm{rs}=0,534)$ e negativas com a temperatura $(\mathrm{rs}=-0,647)$ e horário $(\mathrm{rs}=-0,755)$. T. angustula apresentou correlações significativas positivas com $P$. droryana ( $\mathrm{rs}=0,736)$, E. fulvofasciata $(\mathrm{rs}=0,505)$, luminosidade ( $\mathrm{rs}=0,291)$ e negativas com horário $(\mathrm{rs}=-0,397)$ e temperatura ( $\mathrm{rs}=-0,310)$. A. mellifera correlacionou-se positivamente com $N$. testaceicornis ( $\mathrm{rs}=0,559), T$. angustula $(\mathrm{rs}=0,387), P$. droryana $(\mathrm{rs}=0,564), E$. fulvofasciata $(\mathrm{rs}=0,285)$, umidade $(\mathrm{rs}=0,577)$ e negativamente com horário $(\mathrm{rs}=-0,638)$ e temperatura $(\mathrm{rs}=-0,670)$. $P$. droryana apresentou correlações significativas positivas com E. fulvofasciata $(\mathrm{rs}=0,419)$, umidade $(\mathrm{rs}=0,338)$ e negativamente com horários ( $\mathrm{rs}=-$ $0,544)$, temperatura $(\mathrm{rs}=0,563)$ e vento $(\mathrm{rs}=0,227)$. E. fulvofasciata correlacionou-se positivamente com umidade $(\mathrm{rs}=0,265)$ e luminosidade $(\mathrm{rs}=0,305)$ e negativamente com horário $(\mathrm{rs}=0,403)$.

$N$. testaceicornis, $T$. angustula, A. mellifera, P. droryana e E. fulvofasciata apresentaram correlações negativas com os horários do dia. Isto é compreensível pois, nesta época do ano (Primavera/Verão) a temperatura é alta no meio do dia e, assim, forrageiam com maior intensidade nas horas mais frescas do período da manhã. Exceto E. fulvofasciata, as demais abelhas apresentaram correlações negativas com a temperatura. Entretanto, ABROL (1990) em seus estudos sobre a polinização da alfafa, observou que a abundância das abelhas mostrou-se positivamente correlacionada com a temperatura do ar, intensidade luminosa, radiação solar e concentração do açúcar no néctar, e mostrou-se negativamente correlacionada com a umidade relativa. Já a luminosidade, foi o único fator ambiental que se correlacionou positivamente com T. angustula e E. fulvofasciata, demonstrando que essas abelhas apresentaram certa preferência por luminosidade alta. 


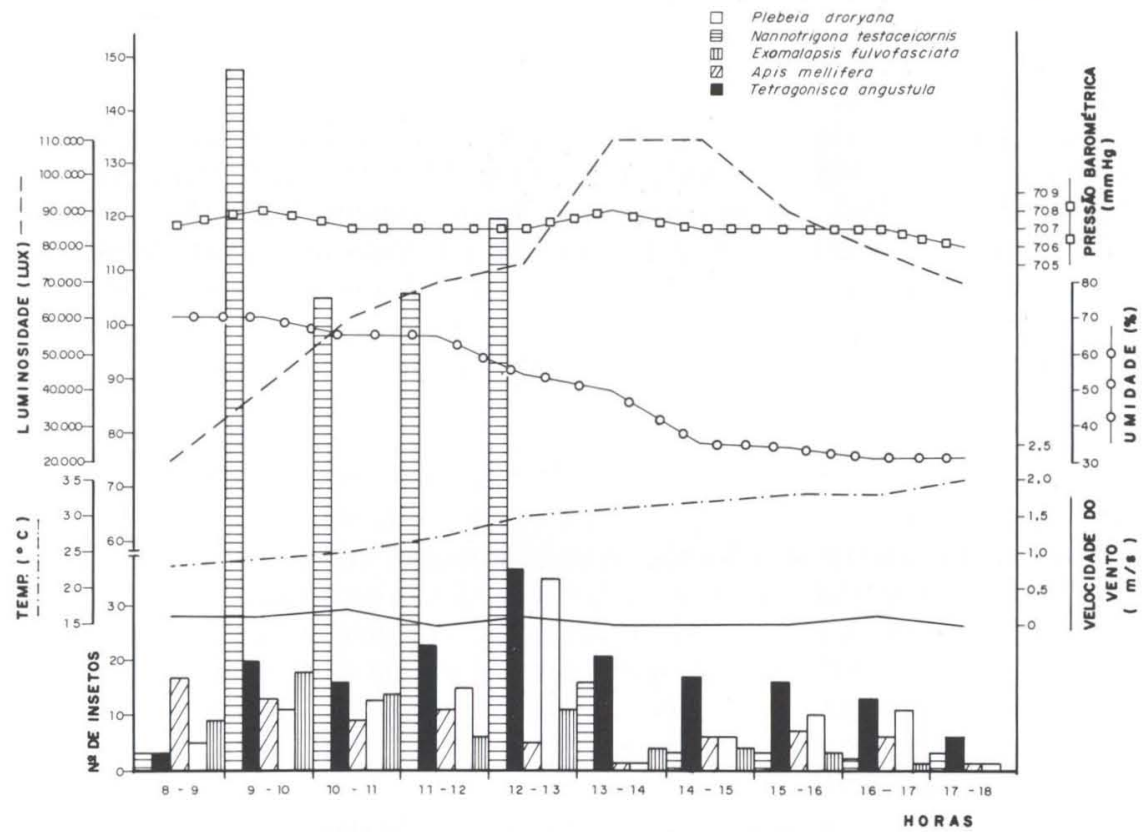

Fig. 4. Distribuição das cinco espécies de abelhas mais freqüentes em diferentes horários, correlacionando com a luminosidade, temperatura, velocidade do vento, umidade e pressão barométrica da coleta 3 realizada na planta L3 durante o período de floração de Lagerstroemia speciosa Pers. (Lythraceae) no ano de 1990.

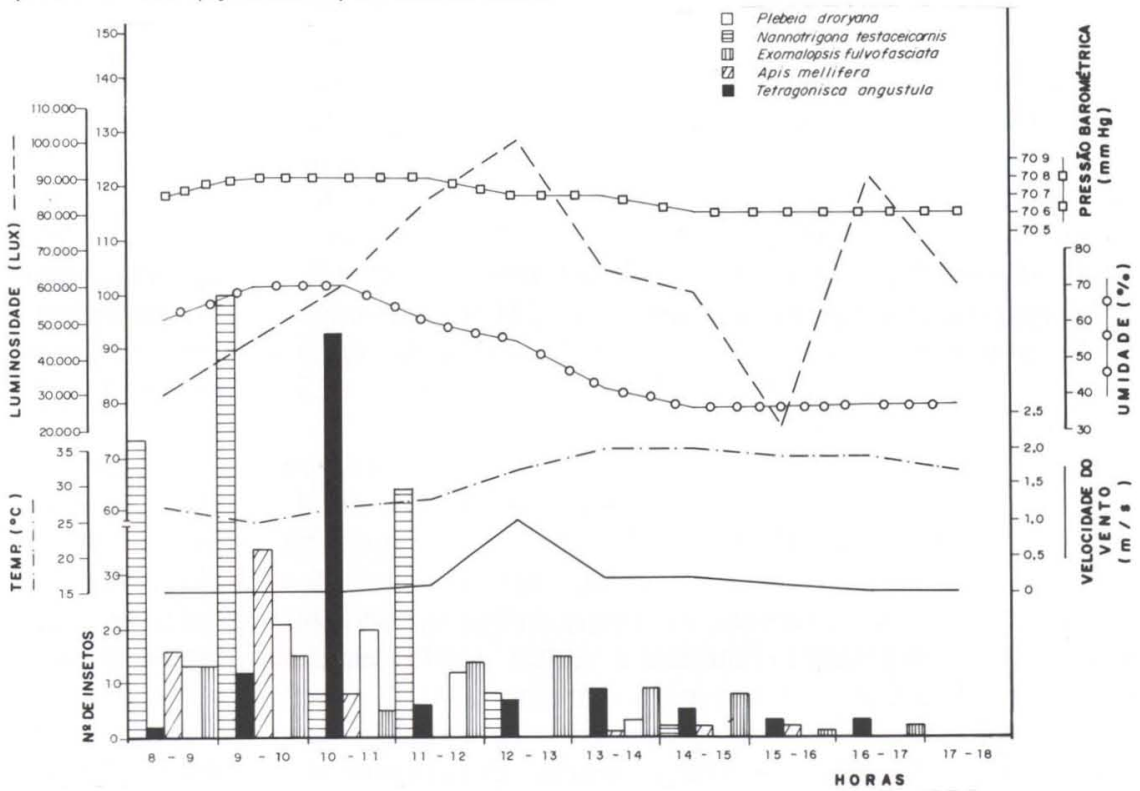

Fig. 5. Distribuição das cinco espécies de abelhas mais freqüentes em diferentes horários, correlacionando com a luminosidade, temperatura, velocidade do vento, umidade e pressão barométrica da coleta 4 realizada na planta $L 4$ durante o período de floração de Lagerstroemia speciosa Pers. (Lythraceae) no ano de 1990.

Revta bras. Zool. 16 (2): 397 - 407, 1999 


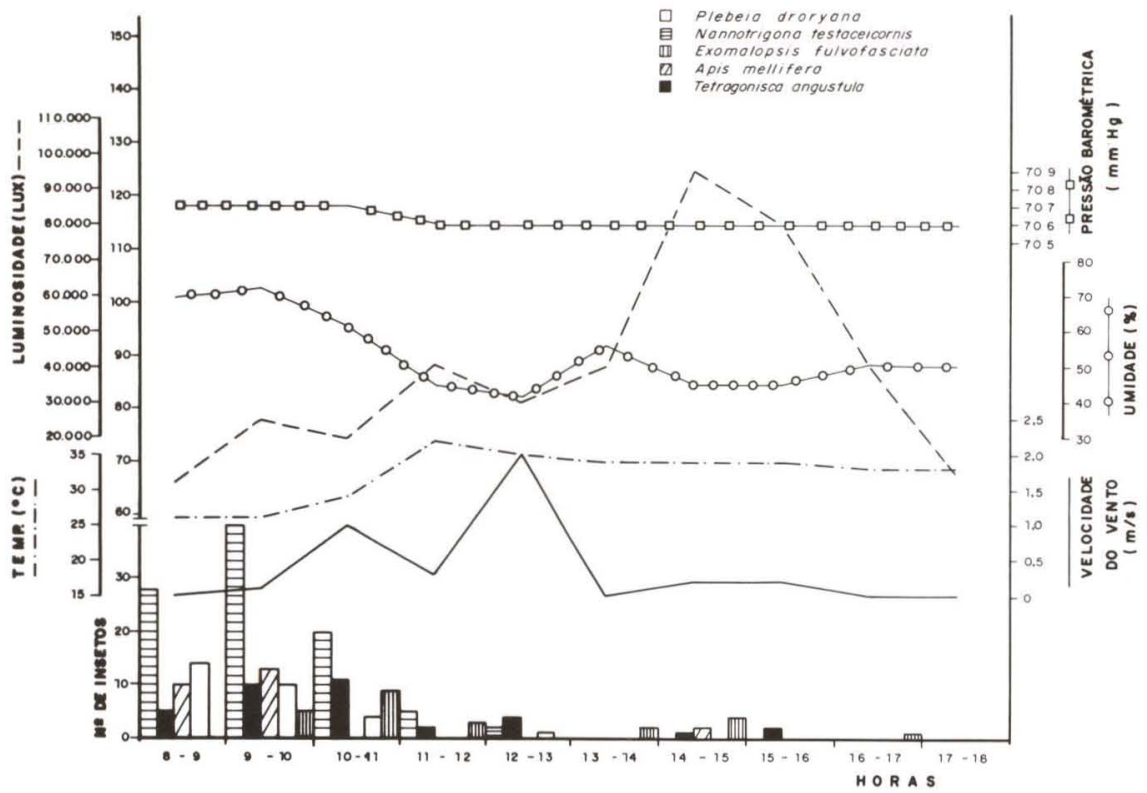

Fig. 6. Distribuição das cinco espécies de abelhas mais freqüentes em diferentes horários, correlacionando com a luminosidade, temperatura, velocidade do vento, umidade e pressão barométrica da coleta 5 realizada na planta L5 durante o periodo de floração de Lagerstroemia speciosa Pers. (Lythraceae) no ano de 1990.

Dentre os insetos visitantes, as abelhas nativas, Bombus morio (Swederus, 1787), B. atratus Franklin, 1913, Centris tarsata Smith, 1874, Centris flavifrons Fabricius, 1775, Xylocopa frontalis (Olivier, 1789), Xylocopa suspecta Camargo \& Moure, 1988, Eulaema nigrita Lepeletier, 1841 e E. fulvofasciata por apresentarem características como tamanho corpóreo, pilosidade e comportamento de contactar os órgãos reprodutores, estão mais adaptadas à flor e realizam a polinização cruzada com maior eficiência, a despeito de suas freqüências não atingirem $5 \%$. Talvez isso se deva ao fato de que a maioria desses insetos apresentam colônias pequenas, não ultrapassando de algumas dezenas de indivíduos.

Algumas vezes foram observados filetes quebrados em duas ou três partes, devido ao impacto provocado pelas mamangavas ao pousarem com muita velocidade nas flores. O impacto do corpo das mamangavas sobre as anteras, resulta em uma "núvem" de grãos de pólen. Devido à pilosidade corpórea que apresentam, as mamangavas funcionam como uma escova, pois ficam com o corpo e pernas repletos de pólen. Desta forma, podem polinizar pelo contato corporal e também através dos grãos de pólen soltos que caem acidentalmente no estigma das flores adjacentes (Fig. 7).

As vespas Protonectarina sylveirae (de Saussure, 1854), Protopolybia exigua (de Saussure, 1854) e Polybia paulista $H$. von Ihering, 1896 foram consideradas polinizadoras ocasionais. Elas apresentaram uma freqüência de distribuição constante através do dia sendo observadas retirando pêlos da corola e coletando néctar. 


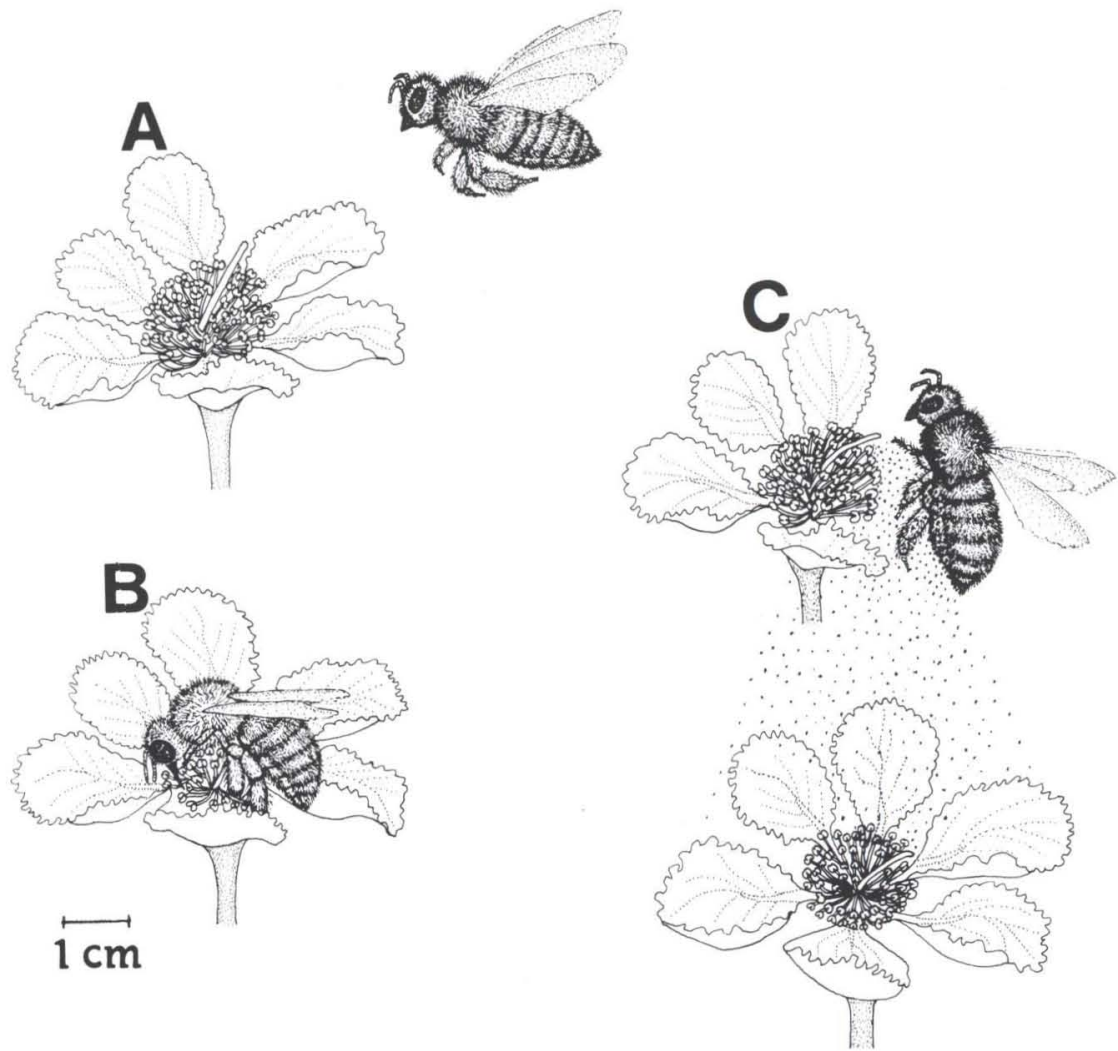

Fig.7. Seqüência de coleta de pólen e/ou néctar das mamangavas nas flores de Lagerstroemia speciosa Pers. (Lythraceae). (A) Polinizador voando localiza a flor, (B) polinizador coletando pólen das anteras, (C) polinizador saindo da flor provoca uma "núvem de grãos de pólen" os quais caem sobre as outras flores. Posteriormente irá visitar outras flores e contactar com os órgãos reprodutores, realizando a polinização.

Os Coleoptera, considerados roubadores primários, alimentavam-se das flores e os Lepidoptera e Diptera procuravam as flores para a obtenção do néctar.

Quanto aos testes de polinização manual (Tab. III) verificou-se que a autopolinização ocorreu em $27,77 \%$. Já, a produção de frutos em condições naturais foi de $4,86 \%$, maior que a encontrada para o grupo controle (12\%). A geitonogamia ocorreu em $32 \%$. As flores emasculadas desenvolveram frutos (10\%) indicando que ocorre também a apomixia. A xenogamia foi o sistema predominante de reprodução $(60,86 \%)$. VAUGHTON (1991) em seu trabalho com Banksia spinulosa Sm., 1981 verificou que a adição de pólen cruzado e de nutrientes aumentou significativamente a produção de frutos, indicando que ambos fatores são limitantes ao sucesso reprodutivo da planta. 
Tabela III. Testes de reprodução manual em Lagerstroemia speciosa Pers. (Lythraceae).

\begin{tabular}{lccc}
\hline \multicolumn{1}{c}{ Testes de reprodução } & Número de flores & Número de frutos & Sucesso (\%) \\
\hline Autopolinização manual com pólen da mesma flor (Autogamia) & 18 & 5 & 27,77 \\
Autopolinização manual com pólen de flor diferente (Geitonogamia) & 25 & 8 & 32,00 \\
Polinizaçăo cruzada (Xenogamia) & 23 & 14 & 60,86 \\
Emasculação (Apomixia) & 20 & 2 & 10,00 \\
Autopolinizaçăo espontânea (Autogamia espontånea) & 25 & 3 & 12,00 \\
\hline
\end{tabular}

Acredita-se que em decorrência das estruturas reprodutivas se posicionarem de maneira que favoreça a deposição do pólen no estigma, o sucesso reprodutivo é incrementado pelos agentes polinizadores. A presença de grandes abelhas nas flores e o seu comportamento sugeriu que essas podem promover a autopolinização e também ser as responsáveis por certa taxa de cruzamento.

A maior abundância de algumas espécies, em particular, $N$. testaceicornis, $T$. angustula, A. mellifera, $P$. droryana e $E$. fulvofasciata sugere que estas espécies estariam apresentando uma maior adaptabilidade na ocupação de ambientes urbanizados.

\section{REFERÊNCIAS BIBLIOGRÁFICAS}

ABROL, D.P. 1990. Pollination activity of alfafa-pollinating subtropical bees $\mathrm{Me}$ gachile flavipes (Hymenoptera: Megachilidae). Tropical Ecology 31: 106-115. FrEE, J.B. 1980. A organização Social das Abelhas (Apis). Temas de Biologia. São Paulo, Ed. da Universidade de São Paulo, 79p.

INOUYE, D.W. 1980. The terminology of floral lacerny. Ecology 61: 1251-1253.

OLIVEIRA-FilHO, A.T. \& L.C.A. OLIVEIRA. 1988. Biologia floral de uma população de Solanum lycocarpum St Hil (Solanaceae) em Lavras, MG. Rev. Brasil. Bot. 11: $23-32$.

RADFORD, A.E.; W.C. DiCKINSON; I.R. MASSEY JR. \& C.R. BELL. 1974. Vascular plants systematics. Harper \& Row, New York, 891p.

VAUGHTON, G. 1991. Variation between years in pollen and nutrient limitation of fruit-set in Banksia spinulosa. Jour. Ecol. 79: 389-400.

VogEL, S. 1983. Ecophysiology of zoophilic pollination, p.560-612. In: O.L. LANGe; P.S. Nobel; C.B. Osmond \& H. Ziegler (Eds). Physiological plant ecology. Berlin, Springer-Verlag, 799p. 